\title{
Effects of pile shape and pile end condition on the lateral response of displacement piles in soft clay
}

\author{
P. TRUONG* and B. M. LEHANE*
}

\begin{abstract}
A series of lateral tests conducted in a centrifuge on displacement piles in kaolin is used to examine the effects of pile shape, pile end-condition and clay overconsolidation on the lateral load transfer $(p-y)$ curves in soft clay. These experimental tests are supported by finite-element analyses, which examine the responses of the circular, square and $\mathrm{H}$ pile sections used in the centrifuge tests. The experimental and numerical results reveal an important effect of pile shape on $p-y$ curves, but no discernible effect of the pile end condition. These results also indicate comparable dependencies of net ultimate pressures on normalised depth and undrained shear strength. The findings enable development of a new formulation for $p-y$ curves in soft clay, which incorporates the effects of pile shape and uses the triaxial compression consolidated undrained shear strength as the reference undrained strength.
\end{abstract}

KEYWORDS: centrifuge modelling; clays; finite-element modelling; model tests; piles \& piling

\section{BACKGROUND}

Piled foundations are commonly required to withstand lateral loads from wind, wave, earthquake and collision forces. The sizing of piles, when lateral loads are dominant, is controlled by the allowable lateral movement or rotation at the pile head at the serviceability limit state and by the lateral geotechnical and structural capacity of the pile at the ultimate limit state. The standard method for predicting the lateral performance of single piles involves discretisation of the pile into beam elements, each with corresponding non-linear, non-interactive springs representing the variation of the net soil resistance with lateral displacement $(y)$. These non-linear springs are referred to as $p-y$ or $P-y$ curves, where $p$ is the net soil resistance per unit length of pile and $P$ is the net soil pressure.

The $P-y$ curves recommended in the literature have been derived from instrumented lateral pile tests. The net soil resistance is calculated directly from the pile bending moments measured in these tests (using the Euler-Bernoulli beam equation) and therefore incorporates the depth dependence of the soil failure mechanisms described by Randolph \& Houlsby (1984) and others. Active and passive wedge failures are expected at shallow depths but, with increasing depth, there is a transition to a flow-around mechanism in the absence of the influence of the free surface. A gap forms on the active side near the pile head when a non-zero undrained shear strength exists at the soil surface. If the pile has a high bending capacity, the pile fails by rotating about a point at depth with net soil resistance on the pile below this rotation point acting in the same direction as the applied load to provide lateral and moment equilibrium. A component of base shear may also be significant for large-diameter piles where rotation causes large movements at the pile toe.

A pile's flexural rigidity clearly has a significant effect on its overall performance, as quantified, for example, by dimensionless stiffness coefficients proposed by Poulos \& Hull (1989). However, Suryasentana \& Lehane (2016),

Manuscript received 11 November 2016; revised manuscript accepted 8 November 2017. Published online ahead of print 15 December 2017.

Discussion on this paper closes on 1 February 2019, for further details see p. ii.

* School of Civil, Environmental \& Mining Engineering, The University of Western Australia, Crawley, WA, Australia.
Fan \& Long (2005) and others have shown that the $P-y$ curves derived from bending moment profiles are independent of the pile rigidity. Suryasentana \& Lehane (2016), for example, derive identical $P-y$ curves for piles with $E I$ values varying by over four orders of magnitude in both loose and dense sand. This finding supports the general success of application of $P-y$ approaches for laterally loaded piles, which are embedded in recommendations such as API (2011).

\section{Ultimate lateral pressures}

The American Petroleum Institute recommendations for predicting lateral pile response (API, 2011) are commonly used by industry for both offshore and onshore piles. The recommended method for soft clay is based almost entirely on a research programme described by Matlock (1970) involving a series of tests on an instrumented $0.324 \mathrm{~m}$ dia., $12.8 \mathrm{~m}$ long, steel circular pile. The ultimate net soil resisting pressure $\left(P_{\mathrm{u}}\right)$ at discrete depths $(z)$ is calculated as

$$
P_{\mathrm{u}}=N_{\mathrm{p}} s_{\mathrm{u}}=\min \left[\left(3 s_{\mathrm{u}_{-} \mathrm{UU}}+\sigma_{\mathrm{v}}^{\prime}+J \frac{s_{\mathrm{u}_{-} \mathrm{UU}} z}{D}\right), 9 s_{\mathrm{u}_{-} \mathrm{UU}}\right]
$$

where $s_{\mathrm{u} \_\mathrm{UU}}$ is the clay's undrained strength measured in an unconsolidated undrained (UU) triaxial compression test; $N_{\mathrm{p}}$ is a dimensionless lateral capacity factor; $D$ is the pile diameter; $\sigma_{\mathrm{v}}^{\prime}$ is the vertical effective stress; and $J$ is a dimensionless empirical constant assumed by Matlock (1970) to equal $0 \cdot 5$ for offshore soft clays similar to Gulf of Mexico clay. The depth dependence of $N_{\mathrm{p}}$ embodied in equation (1) reflects the evolution from the shallow wedgetype mechanism to the deep flow-around mechanism, with $N_{\mathrm{p}}$ increasing to a maximum value of 9 at depth.

Analytical and numerical studies have shown that $N_{\mathrm{p}}$ for the deep flow-around mechanism is larger than the value of 9 adopted in API (2011). For example, using separate analytical approaches, Randolph \& Houlsby (1984), Murff \& Hamilton (1993) and Martin \& Randolph (2006) derived a range for $N_{\mathrm{p}}$ of $9-10$ for smooth piles and 10-12 for rough piles. Three-dimensional (3D) finite-element analyses by Templeton (2009), Jeanjean (2009) and Tzivakos \& Kavvadas (2014) reported $N_{\mathrm{p}}$ values for a rough pile at $z>3 D$ of between approximately 12 and 15 . 
Recent instrumented lateral pile experiments in (nominally) normally consolidated clay described by Jeanjean (2009) indicate that, withstanding some evident nonuniformities in the sample, $N_{\mathrm{p}}$ values increase from about 10 at $z / D=1 \cdot 5$ to about 16 at $z / D=10$; the operational $s_{\mathrm{u}}$ value used by Jeanjean (2009) for calculation of $N_{\mathrm{p}}$ was that corresponding to an average undrained shear strength gradient typical of a normally consolidated clay of $1 \cdot 2$ to $1.25 \mathrm{kPa} / \mathrm{m}$, which equated to a cone penetration test (CPT) cone factor $\left(N_{k}\right)$ of 13 in the experiments.

\section{Pile shape}

Theoretical support for $N_{\mathrm{p}}$ factors has been provided for wished-in-place circular piles using the method of characteristics and wedge analyses (e.g. Randolph \& Houlsby, 1984; Murff \& Hamilton, 1993; Martin \& Randolph, 2006). Such mechanisms have also been observed in 3D finite-element simulations of laterally loaded piles with a circular crosssection (e.g. Truong \& Lehane, 2014; Tzivakos \& Kavvadas, 2014). There is not, however, any comparable research performed on the effect of pile shape on these mechanisms and on the resulting $P-y$ response. Choi et al. (2014) examined the differences between rectangular and square piles in an elastic soil, but noted no significant effect of shape. In contrast, Suryasentana \& Lehane (2016) employed 3D finiteelement non-linear analyses for piles in sand to conclude that square piles were more efficient than circular piles at resisting lateral load. In particular, they found that, for a given pile flexural rigidity and a fully rough interface, the lateral response of a square pile was approximately equal to that of a circular pile with the same perimeter.

\section{Operational undrained shear strength}

The relatively wide range of reported $N_{\mathrm{p}}$ values is partly attributable to the operational undrained strength $\left(s_{\mathrm{u} \_ \text {op }}\right)$ assumed for its derivation and arises because of the wellknown effects of sampling disturbance, shearing mode, anisotropy and shearing rate on any specific $s_{\mathrm{u}}$ measurement. API (2011) recommends use of the $s_{\mathrm{u}_{-} \mathrm{UU}}$ on vertically oriented specimens, but the correspondence between this measure of undrained strength and that of $s_{\mathrm{u} \_ \text {op }}$ operating within the soil mechanisms in the vicinity of a laterally loaded pile is unclear and likely to vary from site to site. Anderson et al. (2003) used the API (2011) recommendations to predict lateral pile behaviour in seven case histories employing $s_{\mathrm{u}}$ values assessed from a range of different in situ tests. They found that equation (1) gave the best predictions when the operational undrained strength was derived from the net cone resistance $\left(q_{\mathrm{c}}\right)$ of the CPT using a cone factor of 15 . However, the soil adjacent to most of the piles considered did not reach ultimate conditions and the values of $P_{\mathrm{u}}$ in each test were uncertain. In addition to in situ measurements of $N_{\mathrm{p}}$, the relationship between $s_{\mathrm{u} \_ \text {op }}$ and the single isotropic $s_{\mathrm{u}}$ value used in analytical and finite-element analyses, discussed above, is also not clear and requires investigation.

\section{Installation effects}

There is little information available to assess the influence of the pile installation method on pile lateral response. No systematic differences due to different installation methods have been identified in soft clays and, based on observations described in Gabr et al. (1994) and elsewhere, this may be presumed to be because the lateral response is controlled by soil extending some distance away from the zone of large installation-induced disturbance. Reese \& Van Impe (2011) show how the process of bored pile installation in both sand and clay causes little change to the CPT $q_{\mathrm{c}}$ values in its vicinity, while Tomlinson \& Woodward (2014) state that there is unlikely to be any long-term difference between the lateral performance of a driven and a bored pile in cohesive soils. It is clear, however, that further research in this area is required.

\section{Conclusion}

Based on the limitations outlined above, this paper describes the results from a centrifuge testing programme designed to address the issues of pile shape, operational strength and installation disturbance in normally consolidated and lightly overconsolidated kaolin. 3D finite-element analyses are presented to examine the influence of shape for wished-in-place piles in normally consolidated clay. The research presented leads to a new set of recommendations for $P-y$ curves for piles in soft clay.

\section{CENTRIFUGE TESTS \\ Test equipment}

The centrifuge tests were conducted in the University of Western Australia (UWA), 1.2 m dia. drum centrifuge; a full description of this centrifuge is provided in Stewart et al. (1998). The first set of lateral pile tests was conducted at $80 \mathrm{~g}$ with a sample overconsolidation ratio (OCR) of 1 ; the second was performed at $40 \mathrm{~g}$ with $\mathrm{OCR}=2$. The schedule of pile tests is summarised in Table 1 and involved tests on circular, square and $\mathrm{H}$ section piles. It is noted that $B$ denotes the width of the square and $\mathrm{H}$ piles and the diameter of the circular piles. Corresponding end pieces were manufactured for each of the hollow sections to enable investigation of

Table 1. Lateral pile testing schedule in the drum centrifuge at UWA

\begin{tabular}{|c|c|c|c|c|c|c|c|c|c|}
\hline Test no. & Shape & Toe & $B^{*}: \mathrm{mm}$ & $L: \mathrm{mm}$ & $t: \mathrm{mm}$ & $e: \mathrm{mm}$ & $\boldsymbol{g}$ level & $E I$ (prototype): $\mathrm{kNm}^{2}$ & OCR \\
\hline 1 & Circular & Closed & 11 & 135 & 1 & 17 & 80 & $1.00 \times 10^{6}$ & 1 \\
\hline 2 & Circular & Open & 11 & 132 & 1 & 17 & 80 & $1.00 \times 10^{6}$ & 1 \\
\hline 3 & Square & Closed & 12 & 135 & 1 & 19 & 80 & $2 \cdot 86 \times 10^{6}$ & 1 \\
\hline 4 & Square & Open & 12 & 133 & 1 & 19 & 80 & $2.86 \times 10^{6}$ & 1 \\
\hline 5 & $\mathrm{H}$ section & $\mathrm{n} / \mathrm{a}$ & 10 & 135 & 1 & 19 & 80 & $1.81 \times 10^{6}$ & 1 \\
\hline 6 & Circular & Closed & 11 & 134 & 1 & 17 & 40 & $63 \times 10^{3}$ & 2 \\
\hline 8 & Square & Closed & 12 & 134 & 1 & 17 & 40 & $179 \times 10^{3}$ & 2 \\
\hline 9 & Square & Open & 12 & 132 & 1 & 18 & 40 & $179 \times 10^{3}$ & 2 \\
\hline 10 & $\mathrm{H}$ section & $\mathrm{n} / \mathrm{a}$ & 10 & 131 & 1 and $1 \cdot 8 \dagger$ & 20 & 40 & $113 \times 10^{3}$ & 2 \\
\hline
\end{tabular}

*Dimension includes epoxy coating.

$\dagger$ Flange and web thickness $=1 \mathrm{~mm}$ and $1.8 \mathrm{~mm}$, respectively. 
effects of soil displacement induced during closed-ended and open-ended pile installation.

The piles were instrumented with eight pairs of strain gauges arranged with half bridge configurations. Photographs of the test piles showing their cross-sections and the locations of the strain gauges are provided in Fig. 1. The strain gauges were protected and waterproofed by a $0.5 \mathrm{~mm}$ thick coating of epoxy; this thickness of epoxy is included in the test pile dimensions summarised in Table 1. End pieces fitted to the base of the hollow section piles were used for closed-ended pile installation and each increased the overall pile length by $2 \mathrm{~mm}$. Each of the instrumented piles was calibrated on a laboratory bench in a cantilever mode by hanging weights from the pile toe while the head was fixed to the bench with clamps. The corresponding voltage readings in the strain gauges were recorded to determine calibration factors to convert voltage output to bending moment.

Lateral loading was applied using a loading arm (see Fig. 1), attached and controlled by the actuator in the drum centrifuge. This loading configuration is shown in Fig. 2. The loading arm had a rounded end to facilitate application of a point load to the pile head.

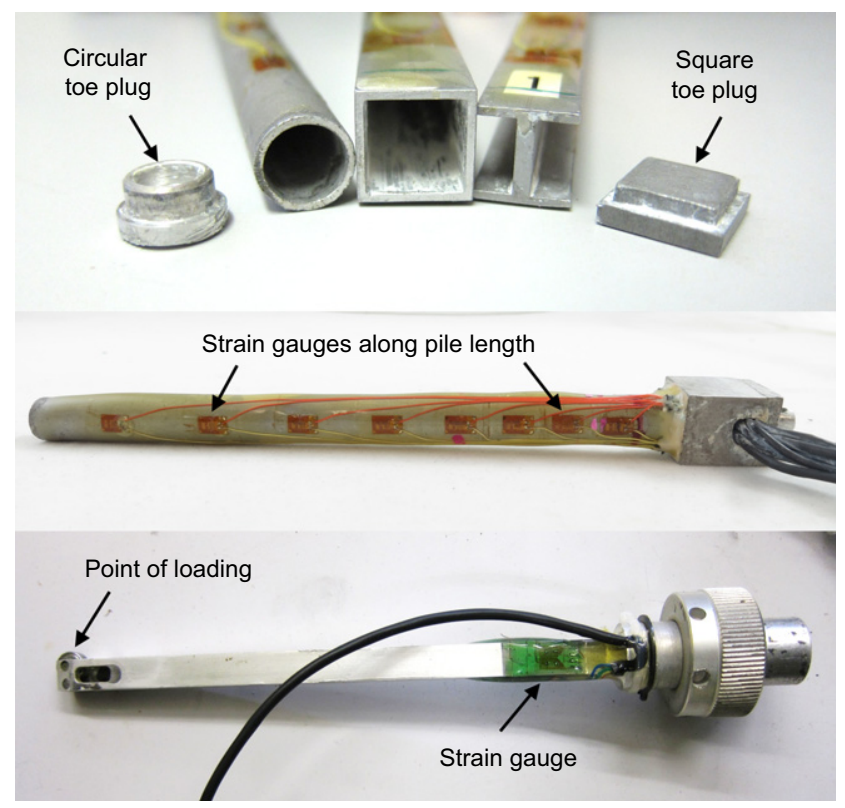

Fig. 1. Centrifuge test piles and loading arm
Clay properties and preparation

The kaolin clay used is commercially available and its properties are summarised in Lehane et al. (2009). The clay has $100 \%$ fines content with $70 \%$ clay fraction, liquid limit of $61 \%$ and plasticity index of $34 \%$. The undrained strength ratio measured in both simple shear and isotropic triaxial compression tests on normally consolidated kaolin, $\left(s_{\mathrm{u}} / \sigma_{\mathrm{v}}^{\prime}\right)_{\mathrm{nc}}$, varied between 0.25 and 0.3 while the equivalent ratio in triaxial extension was approximately $0 \cdot 15$. The undrained strength ratios are consistent with the following relationship proposed by Ladd et al. (1977)

$$
\frac{s_{\mathrm{u}}}{\sigma_{\mathrm{v}}^{\prime}}=\left(\frac{s_{\mathrm{u}}}{\sigma_{\mathrm{v}}^{\prime}}\right)_{\mathrm{nc}} \mathrm{OCR}^{0.8}
$$

The drum sample was prepared by mixing a slurry at two times the liquid limit in a vacuum chamber. This slurry was then fed through a tube into the spinning drum channel, where it was allowed to consolidate under a centrifuge acceleration of $80 \mathrm{~g}$ for 4 days. The channel was topped up a number of times over this period and had a height of about $170 \mathrm{~mm}$ when fully consolidated. A small thickness of clay was scraped off the top of the sample to ensure a level surface. Once the tests at $80 \mathrm{~g}$ were completed, the centrifuge acceleration was reduced to $40 \mathrm{~g}$ and the sample allowed to swell for a period of $16 \mathrm{~h}$ before the first test at $\mathrm{OCR}=2$ commenced.

T-bar tests were conducted during the testing programme at $80 \mathrm{~g}$ and $40 \mathrm{~g}$. The T-bar undrained strengths $\left(s_{\mathrm{u}} \mathrm{Tbar}\right)$ were determined by applying a T-bar bearing factor of 10.5 to the penetration resistance after correction for effects of lateral stress on the load cell output, buoyancy and shallow penetration (White et al., 2010; Zhao et al., 2016). The $s_{\text {u_Tbar }}$ profiles are presented using the scaled prototype depth in Fig. 3. These show some spatial variation with T-bar undrained strength ratios generally varying from the mean $\left(s_{\mathrm{u} \_ \text {Tbar }} / \sigma_{\mathrm{v}}^{\prime}=0 \cdot 23\right)$ with a coefficient of variation of $9 \%$ and given by the following equation

$$
\frac{s_{\mathrm{u} \_ \text {Tbar }}}{\sigma_{\mathrm{v}}^{\prime}}=(0.23 \pm 0.02) \mathrm{OCR}^{0.8}
$$

The strength variation indicated in this equation was accounted for in the data processing by correlating each pile test result with the closest T-bar test. Fig. 3 also shows that extrapolation of the $s_{\mathrm{u} \_ \text {Tbar }}$ profiles to the surface gives small non-zero values; this is partly due to minor overconsolidation induced by a slight drop in water level below the clay surface during sample preparation. The average rate of increase

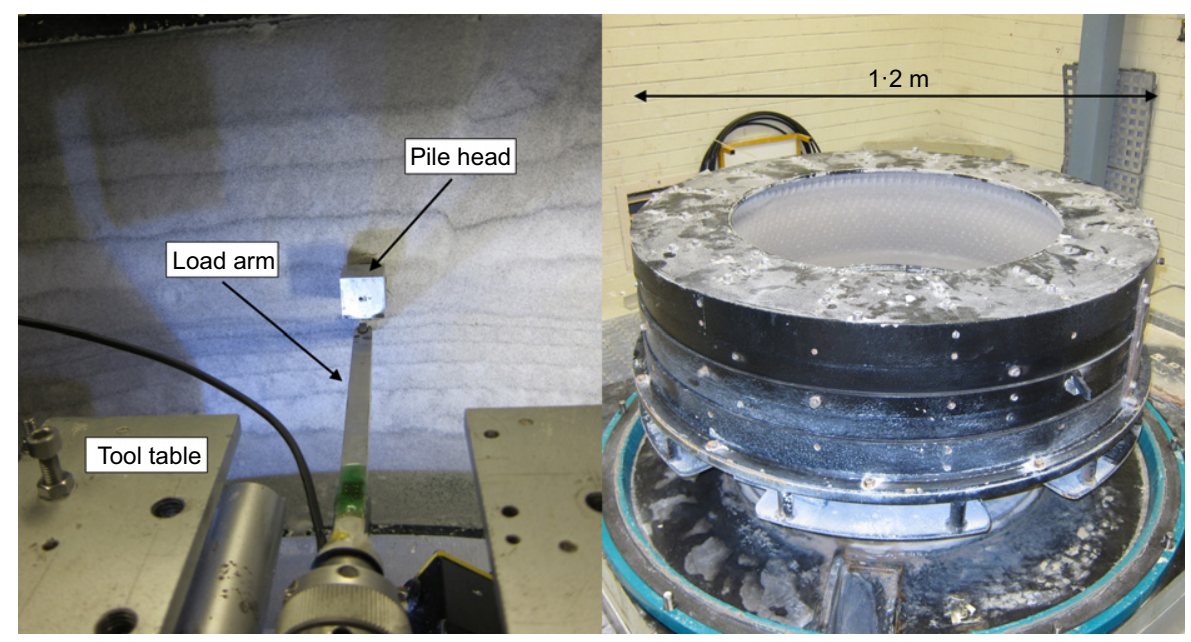

Fig. 2. Loading configuration and UWA drum centrifuge 


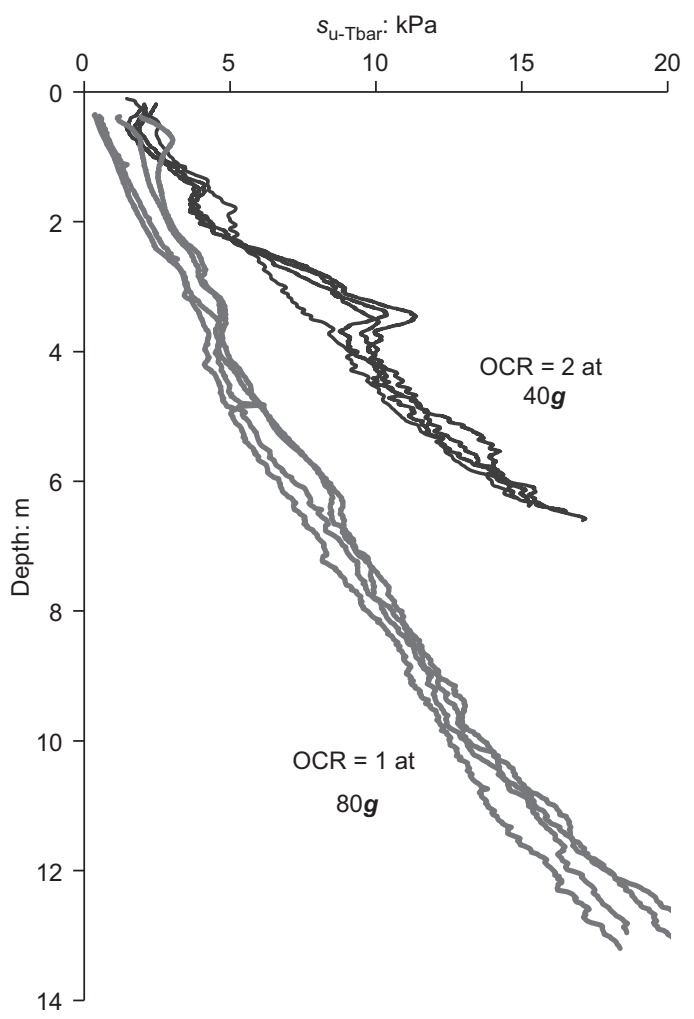

Fig. 3. Undrained shear strength measured from T-bar at $80 \mathrm{~g}$ $(\mathrm{OCR}=1)$ and $40 \mathrm{~g}(\mathrm{OCR}=2)$

of $s_{\mathrm{u} \_ \text {Tbar }}$ with depth $(k)$ for a submerged unit weight of $6 \mathrm{kN} / \mathrm{m}^{3}$ is approximately $1.4 \mathrm{kPa} / \mathrm{m}$ and $2.4 \mathrm{kPa} / \mathrm{m}$ at $\mathrm{OCR}=1$ and 2 , respectively.

\section{Test procedure}

The actuator in the drum centrifuge was used for pile installation and loading. Each pile was jacked into the sample at $1 \boldsymbol{g}$ at a rate of $2 \mathrm{~mm} / \mathrm{s}$ using the actuator. It is noted that Taylor (1995) found little difference in capacities mobilised by piles installed at $1 \mathrm{~g}$ compared to those installed in flight. After pile installation, the lateral loading arm was installed onto the actuator and moved into position for loading. The sample was then ramped up to the designated $\boldsymbol{g}$-level and allowed at least $4 \mathrm{~h}$ of re-consolidation before carrying out the lateral load test. During ramp up, water was slowly added to the channel so that all tests would be conducted under fully saturated conditions with free water on the clay surface. The lateral load was applied at a rate of $0.3 \mathrm{~mm} / \mathrm{s}$ at the eccentricities above the soil surface $(e)$ shown in Table 1 ; this rate of loading equates to approximately 1.6 pile diameters or widths of lateral movement per minute and led to fully undrained conditions.

\section{CENTRIFUGE TEST RESULTS}

\section{Data processing}

The bending moments $(M)$ at each strain gauge level and at each lateral load level were derived by way of calibration factors with the strain gauge output. $P$ and $y$ values at any particular load level were then calculated from the following equations

$$
p=P \times D=-\frac{\mathrm{d}^{2} M}{\mathrm{~d} z^{2}}
$$

$$
y=\iint M / E I \mathrm{~d} z
$$

where $E I$ is the flexural rigidity of the pile. The yield stress in the aluminium piles was not exceeded at the maximum load in any of the lateral pile tests and therefore the lateral pile failure observed was due to a geotechnical rather than pile structural failure. Various curve-fitting methods were investigated to achieve a curve fit to the $M$ values determined at the strain gauge levels; these included the cubic spline, fifth-order polynomial and fourth-order piecewise polynomial. The cubic spline method was not suitable as the relatively wide spacing of the strain gauges resulted in fluctuations after the second differentiation of $M$ to calculate $P$. The (high) fifth-order polynomial was also not acceptable as it over-predicted the base shear at the pile toe and resulted in unexpected inflection points at shallow depths. The fourthorder piecewise polynomial (using three pieces) gave the lowest error when the evaluated $P-y$ curves were used in a standard load transfer program to reproduce the measured pile head-load displacement curves.

Determination of $y$ using equation (5) requires two known displacements. One of these displacements was measured at the actuator location (i.e. where the lateral load was applied) and the other was assumed to have a zero value where the net soil resistance switched direction - that is, at the inferred point of rotation. This approach was seen to be consistent with the observations from finite-element analyses discussed later.

\section{Ultimate net soil resistance $\left(P_{\mathrm{u}}\right)$}

Because of some lateral variation in the T-bar strength profiles, the soil pressures developed at the lateral capacity of the tested piles $\left(P_{\max }\right)$ are normalised by $s_{\mathrm{u}}$ Tbar and compared at normalised depths $(z / L)$ on Fig. 4(a); a dual $Y$-axis with the approximate $z / B$ value is also provided in this figure, noting that $L / B$ varied between 11 and 13.5 in the experiments. No data are shown at $z / L$ values less than $0 \cdot 1$ (equivalent to $z / B$ less than about 1 ) because of uncertainties associated with sensitivity to both small changes in $S_{\mathrm{u} \_ \text {Tbar }}$ and to the curve-fitting methods. The increase in the normalised net pressure with depth to $z \approx 4 B$ is consistent with the transition from a shallow wedge-type mechanism to flow-around failure, described previously.

By inference from the progression of pile deflections during lateral loading shown for a typical case on Fig. 4(b) (from test 1) and the load transfer curves on Fig. 5 (discussed below), it is clear that mobilised pressures occurring between $z / L$ of 0.7 and 0.9 are below the ultimate values $\left(P_{\mathrm{u}}\right)$ as they are close to the point of pile rotation where lateral movements are small. The relative depth of the point of rotation for all of the centrifuge piles was closely comparable to that seen on Fig. 4(b), which also indicates that the pile response was essentially rigid with $P_{\max } / s_{\mathrm{u}_{-} \text {Tbar }}$ values close to the pile toe being similar to those at $z / L=0 \cdot 7$. The existence of friction at the base of the pile influences evaluated $P_{\max } / s_{\mathrm{u} \text { Tbar }}$ ratios near the toe and these are therefore a less reliable measure of net ultimate lateral resistance.

Figure 4 reveals a substantial effect of pile shape on the ratio of the ultimate pressure to T-bar strength, $P_{\mathrm{u}} / s_{\mathrm{u}_{-} \text {Tbar, }}$ defined as $N_{\text {p_tbar }_{-}}$The ratios for square and $\mathrm{H}$ piles are evidently about $25-40 \%$ higher than the ratios for circular piles, but show no clear dependence on OCR or pile end condition. It should be noted that, although plugging of the open-ended piles (which were installed at $1 \boldsymbol{g}$ ) began after a pile penetration of about $3 B(z / L<0 \cdot 25)$, the close similarity of $N_{\text {p_tbar }}$ for open- and closed-ended piles 


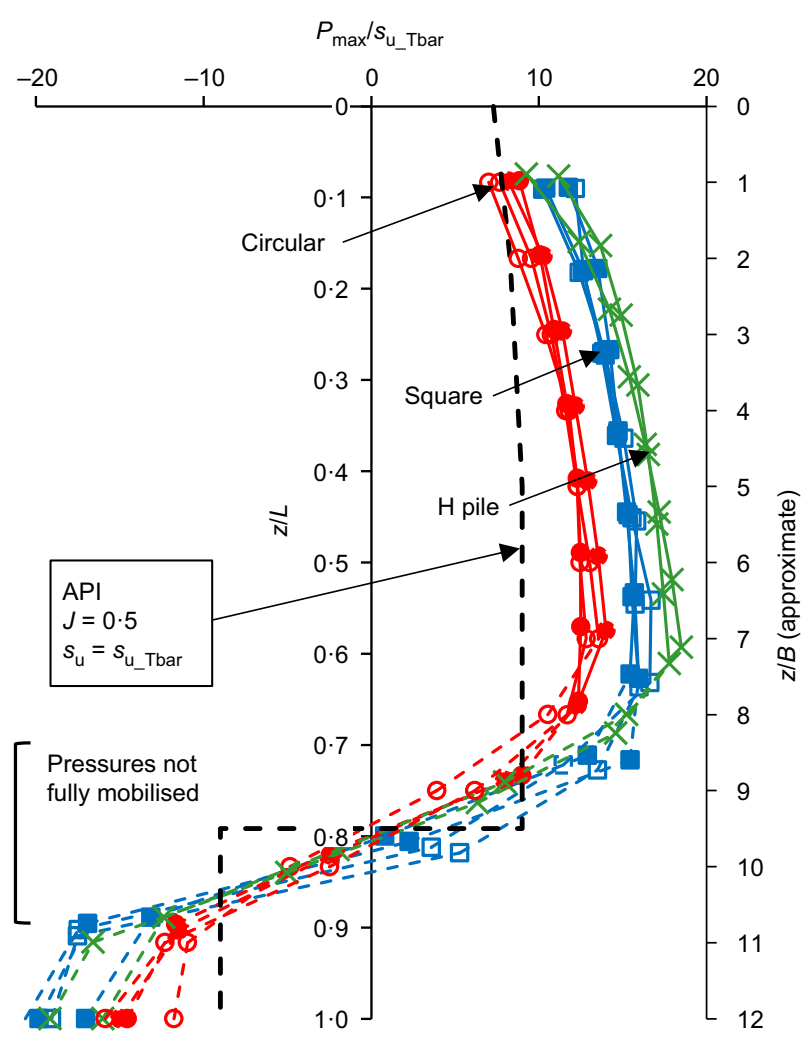

(a)

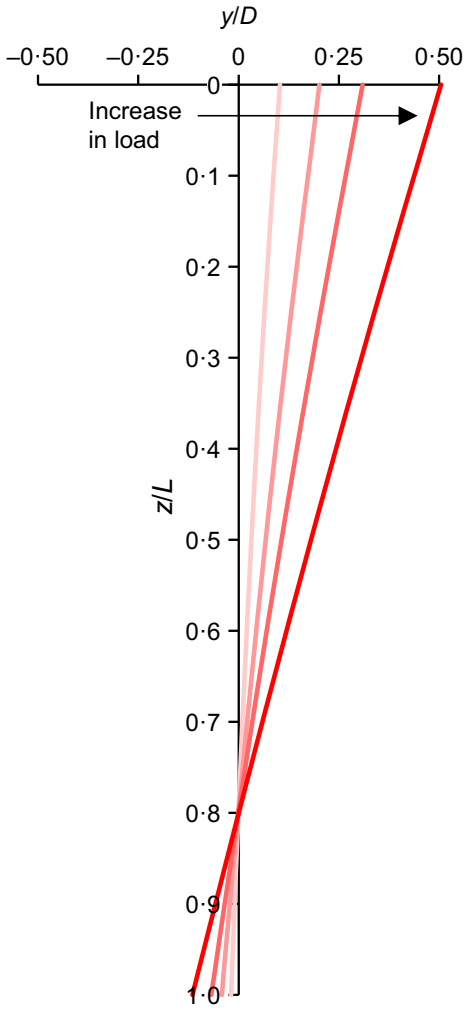

(b)

Fig. 4. (a) Profiles of maximum normalised net lateral resistance for all tests ( $z / B$ axis assumes the mean $B$ value of the test piles) and (b) progression of pile deflection profiles in test 1

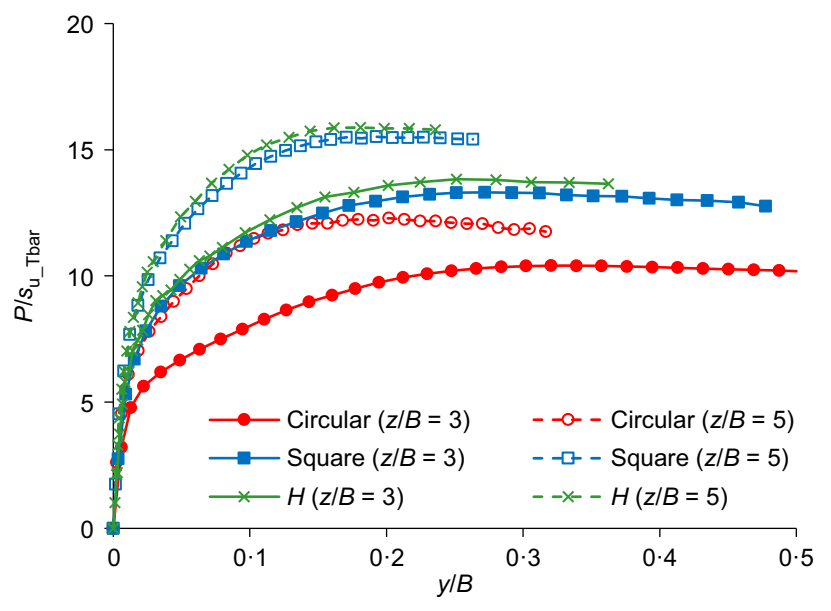

Fig. 5. Normalised load transfer curves for open-ended piles at $z / B$ of 3 and 5 in normally consolidated kaolin

up to this penetration indicates that $N_{\text {p_tbar }}$ is essentially independent of whether the pile was coring or fully plugged at these shallow depths.

$N_{\mathrm{p} \text { Tbar }}$ increases non-linearly with depth up to $z / L=0 \cdot 4$ (or $z / B \sim 5$ ) and has approximate average values between $z / B=3$ and $z / B=7$ of $12 \cdot 4,15 \cdot 5$ and $17 \cdot 1$ for the circular, square and $\mathrm{H}$ piles, respectively. For comparative purposes, Fig. 4 also shows the profile of $N_{\mathrm{p}}$, as deduced using equation (1) following the API (2011) recommendations and equating $s_{\mathrm{u} \_ \text {Tbar }}$ with $s_{\mathrm{u} \_ \text {uu }}$. It is clear that these $N_{\mathrm{p}}$ values are considerably lower than corresponding $N_{\mathrm{p}_{-} \text {Tbar }}$ values and also show a less pronounced dependence on depth to that indicated in the centrifuge tests.

\section{$P-y / B$ curves}

The influence of pile shape, pile end condition and OCR on the variations of net lateral soil pressure $(P)$ with lateral displacement $(y)$ are examined in Figs 5 and 6 . The effects of pile shape are illustrated in Fig. 5 for open-ended piles at $\mathrm{OCR}=1$ at two representative $z / B$ values. This figure plots the variations of $P / s_{\mathfrak{u}_{-} \text {Tbar }}$ against normalised lateral displacement $(y / B)$ for the three different shapes examined. In keeping with the trends indicated on Fig. 4, the ultimate pressures for the square and $\mathrm{H}$ piles are $25-40 \%$ larger than those of the circular piles. Experimental variability and the fact that piles had varying flexural rigidities (see Table 2) do not permit a general conclusion to be made regarding the stiffness of the response. It can be inferred, however, that the stiffness increases as $P_{\mathrm{u}}$ increases. For all the pile tests and for $z / B$ between 2 and 6 , the mean values of $y / B$ required to develop $0 \cdot 25 P_{\mathrm{u}}, 0 \cdot 5 P_{\mathrm{u}}$ and $0 \cdot 75 P_{\mathrm{u}}$ were $0 \cdot 003,0 \cdot 013$ and $0 \cdot 05$, respectively; the associated coefficient of variation for these values was approximately $0 \cdot 25$.

The influence of OCR and pile end condition is illustrated for a typical case in Fig. 6, which plots $P$ values normalised by the respective $P_{\mathrm{u}}$ values against $y / B$ for each pile shape at $z / B=5$. Although there are some differences between the curves for each pile type, it can be concluded that, within the experimental accuracies involved, there is not an observable systematic dependence of the $P / P_{\mathrm{u}}$ plotted against $y / B$ variations on the pile end condition and clay OCR; the same conclusion was inferred for trends shown by $N_{\mathrm{p}_{-} \text {Tbar. }}$ The installation of the piles at $1 \boldsymbol{g}$ and the plugging of the open-ended piles at $z / B>3$ precludes firm conclusions to be drawn in relation to the end condition. Withstanding these issues, the general similarity of $P / P_{\mathrm{u}}$ plotted against $y / B$ variations at shallower depths for closed- and open-ended piles supports the contention that the end condition effects are not significant. 


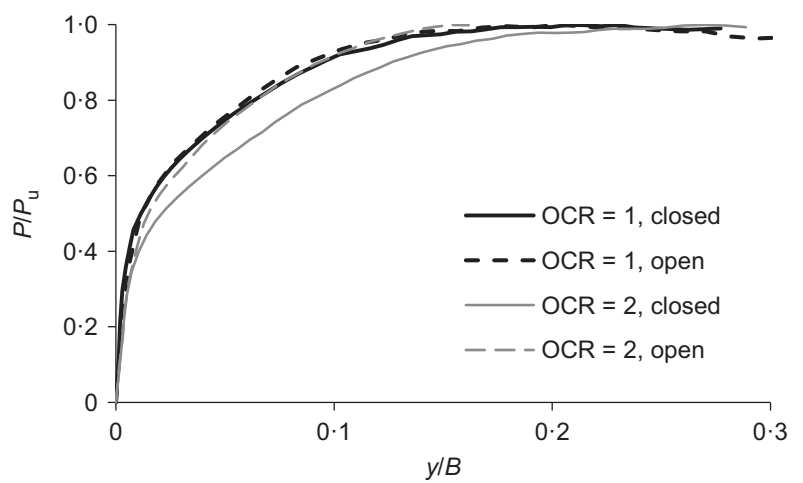

(a)

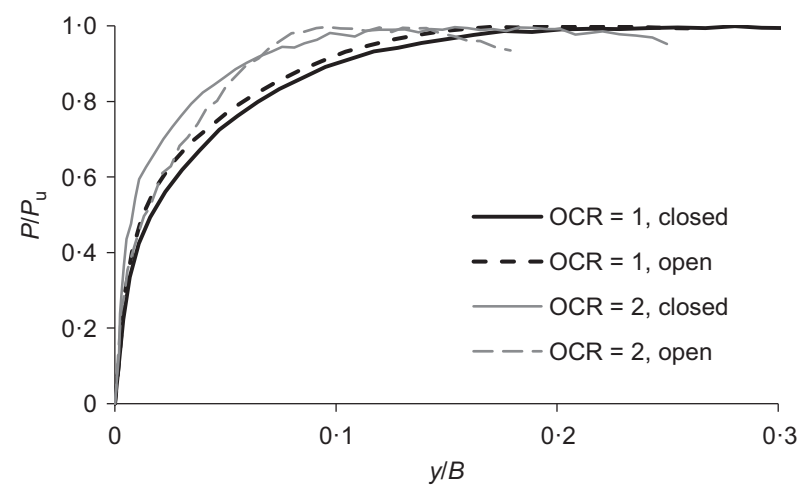

(b)

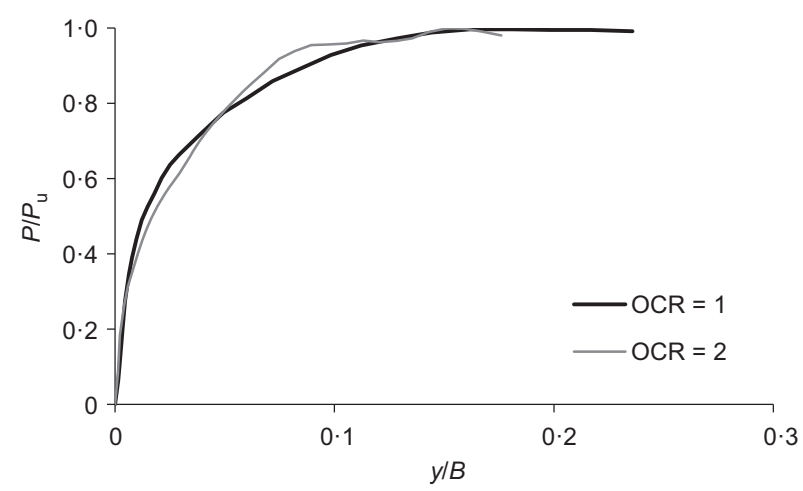

(c)

Fig. 6. Normalised $P-y / B$ curves at $z / B=5$ for (a) circular, (b) square and (c) $\mathrm{H}$ piles

\section{Overall lateral pile response}

As seen in Table 1, the embedment of the piles $(L)$ ranged between $131 \mathrm{~mm}$ and $135 \mathrm{~mm}$, the pile widths varied from 10 to $12 \mathrm{~mm}$ and the eccentricities $(e)$ ranged from $17 \mathrm{~mm}$ to $20 \mathrm{~mm}$. These variations therefore need to be allowed for to provide a clear comparison of the lateral performance of the respective pile types. This comparison was achieved by calculating the response of a centrifuge pile with average dimensions of $B=11 \mathrm{~mm}$ and $L=132 \mathrm{~mm}$ with $e=16.5 \mathrm{~mm}$. The calculations were performed using a standard commercial beam-spring program for laterally loaded piles (ALP; Oasys (2014)) and using the $P-y$ non-linear curves determined at each $z / B$ value for the respective piles as input to the program.

The calculated load-displacement responses of the piles are summarised in Fig. 7. In keeping with published solutions for laterally loaded piles in soft clay (e.g. Fleming et al., 2009), the lateral load is normalised by $k B^{3}$, where $k$ is the average rate of increase of $s_{\mathrm{u} \_ \text {Tbar }}$ with depth at each pile location, with zero strength at the ground surface assumed. Fig. 7 reflects all of
Table 2. Three-dimensional finite-element analyses and ultimate load capacities

Pile properties

\begin{tabular}{l|c}
\hline$B$ (orthogonal to loading) & $0.88 \mathrm{~m}$ \\
$L$ & $10.56 \mathrm{~m}$ \\
$E$ & $1.32 \mathrm{~m}$ \\
$E I-$ circular pile & $1.00 \times 10^{6} \mathrm{kNm}^{2}$ \\
$E I-$ square pile & $2.86 \times 10^{6} \mathrm{kNm}^{2}$ \\
$E I-$ rotated square & $2.86 \times 10^{6} \mathrm{kNm}^{2}$ \\
$E I-$ H pile & $1.81 \times 10^{6} \mathrm{kNm}^{2}$ \\
\hline
\end{tabular}

\begin{tabular}{l|c|c}
\hline Pile shape & $\alpha$ & $H_{\text {ult }}: \mathrm{kN}$ \\
\hline Circular & 1 & 165 \\
Square & 1 & 209 \\
H section & 1 & 217 \\
Circular & $0 \cdot 5$ & 151 \\
Square & $0 \cdot 5$ & 200 \\
H section & $0 \cdot 5$ & 212 \\
Rotated square & 1 & 171 \\
\hline
\end{tabular}

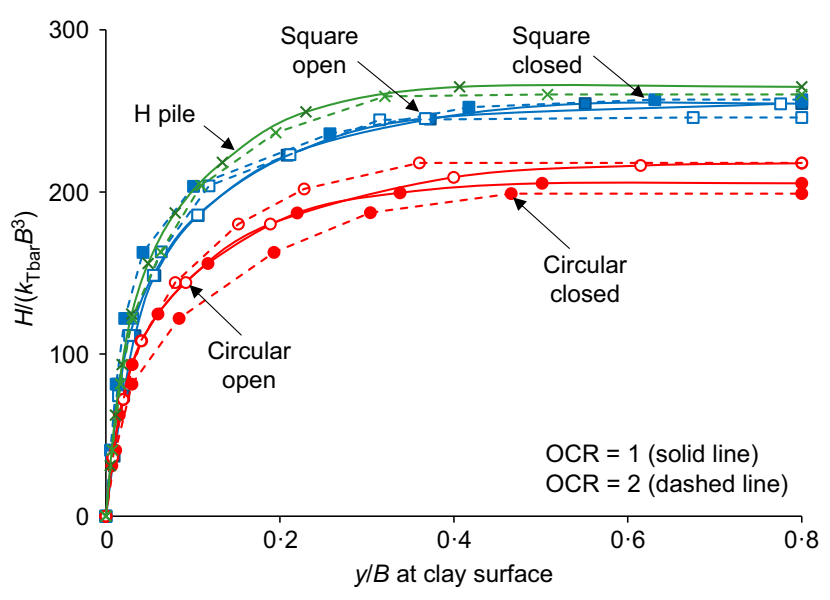

Fig. 7. Normalised load-displacement response of centrifuge tests modified to $L I B=12$ and $e / B=1 \cdot 5$

the trends observed in Figs 5 and 6, namely: $(a)$ the lateral capacity of the square and $\mathrm{H}$ piles is $25-40 \%$ higher than for circular piles; $(b)$ there is no clear effect of pile end condition on the lateral performance of the piles.

It is evident from Figs 5 and 7 that, in terms of pile material volume, $\mathrm{H}$ piles have the most efficient shape to resist lateral load. For circular and square piles with the same volume, the width of the square pile is 0.89 times the diameter of the circular pile. It may be inferred from Figs 5 and 7 that, even with this reduced width dimension, square piles are more efficient at resisting lateral load than circular piles. This trend is investigated numerically in the following.

\section{THREE-DIMENSIONAL NUMERICAL ANALYSES}

Three-dimensional, finite-element, total stress analyses were performed using Plaxis 3D (Plaxis, 2015) to examine the effect of shape on lateral pile capacity and to compare calculations with the centrifuge observations at $\mathrm{OCR}=1$. As shown in Fig. 8, half models with the line of symmetry in the direction of loading were created for each pile shape. Each model was $15 \mathrm{~m}$ wide, $15 \mathrm{~m}$ deep and $40 \mathrm{~m}$ long and comprised approximately one-quarter of a million ten-noded tetrahedral elements. The meshes are very fine in the vicinity of the piles and coarsen with distance from the piles towards 

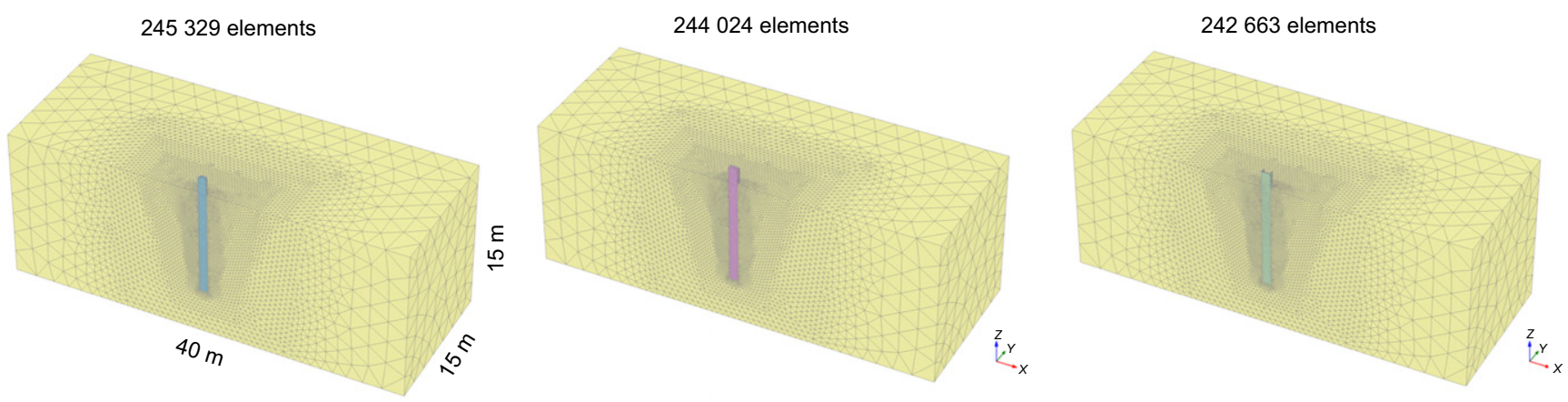

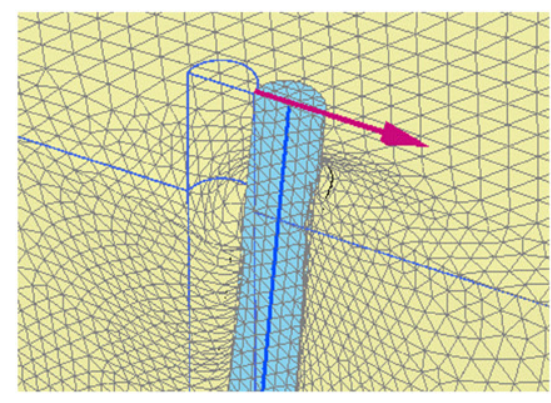

(a)

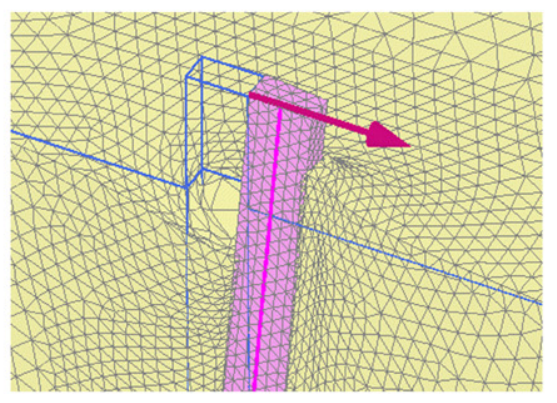

(b)

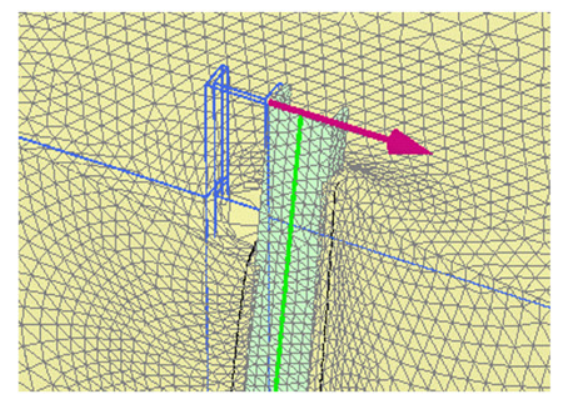

(c)

Fig. 8. Plaxis 3D mesh of half models for (a) circular, (b) square and (c) H-section piles

the model boundaries. The vertical boundary surfaces are fixed in the horizontal direction and the basal boundary is fully fixed. Refinements to the meshes and extensions of the model boundaries were carried out until further refinements did not change the solution.

The soil was modelled as an elastic, perfectly plastic material with a Tresca yield criterion and a specified shear strength $\left(s_{\mathrm{u} \_ \text {FE }}\right)$ increasing linearly with depth at a rate of $k=1 \cdot 4 \mathrm{kPa} / \mathrm{m}$. The ratio of the Young's modulus to shear strength $\left(E_{\mathrm{u}} / s_{\mathrm{u} \_ \text {FE }}\right)$ was assumed constant and equal to 210 ; preliminary analyses showed that this ratio led to computed pile head displacements that were consistent with those measured in the experiments.

The piles were modelled as solid sections using linear elastic volume elements with no yielding permitted (recalling that the centrifuge piles did not display any evidence of yielding). A series of beam elements with very low flexural rigidity located along the centreline of the piles enabled easy extraction of pile bending moments and displacements from the finite-element output. The equivalent prototype dimensions to the mean centrifuge pile dimensions were employed throughout - that is $B=0.88 \mathrm{~m}, L=10.56 \mathrm{~m}$ and $e=1.32 \mathrm{~m}$, which is equivalent to the mean centrifuge dimensions of $B=11 \mathrm{~mm}$ and $L=132 \mathrm{~mm}$ with $e=16.5 \mathrm{~mm}$ scaled linearly by 80 (for tests conducted at $80 \mathrm{~g}$ ). These dimensions are identical to those used in the load transfer analyses presented in Fig. 7. The finite-element analyses also investigated the influence of pile-soil interface roughness by varying the roughness parameter $\alpha$, defined as the ratio of the maximum shear stress that can develop at the interface divided by $s_{\mathrm{u}}$; cases with $\alpha=1$ and $\alpha=0.5$ were considered. In addition, given the relatively efficient performance of the square centrifuge piles, a case where the lateral load was applied orthogonal to the diagonal of the square was also examined; for this case, the diagonal dimension was set equal to $B=0.88 \mathrm{~m}$. The full series of finite-element analyses performed is summarised in Table 2.

\section{Finite-element results}

The computed load displacement results are presented in Fig. 9 in the same format as that employed for the centrifuge

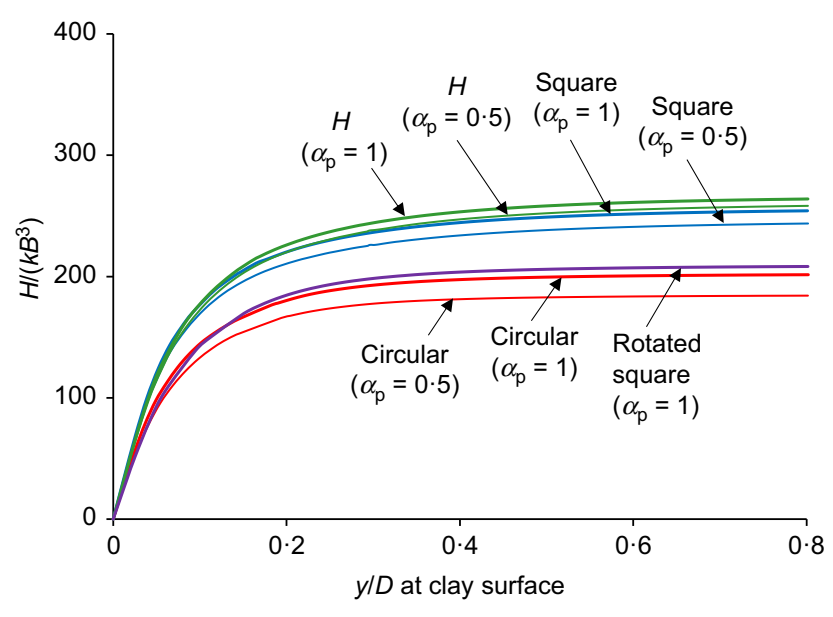

Fig. 9. Normalised load-displacement curves from 3D finite-element analysis

tests in Fig. 7. The calculated $P_{\mathrm{u}}$ and specified $s_{\mathrm{u} \_ \text {FE }}$ profile are used to determine finite-element $N_{\mathrm{p}}$ values, termed $N_{\mathrm{p} \_ \text {FE }}$ factors $\left(=P_{\mathrm{u}} / s_{\mathrm{u}_{-} \mathrm{FE}}\right)$. These are plotted in Fig. 10 in the same format as the $\bar{N}_{\mathrm{p}_{-} \text {Tbar }}$ values in Fig. 4 . It is evident that the relative effects of pile shape indicated in the finite-element analyses are in general agreement with trends shown by the centrifuge piles. The capacity of $\mathrm{H}$ piles is marginally greater than for square piles, but the capacities for both of these shapes are typically $30 \%$ higher than for circular piles. Maximum $N_{\text {p_FE }}$ values, with fully rough conditions $(\alpha=1)$ at $z / B>3$ are $12 \cdot 5,17 \cdot 3$ and $18 \cdot 7$ for the circular, square and $\mathrm{H}$ pile, respectively. For the semi-rough case with $\alpha=0.5$,

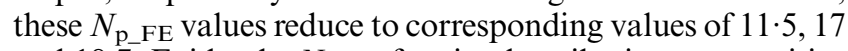
and $18 \cdot 7$. Evidently, $N_{\mathrm{p} \_ \text {FE }}$ for circular piles is most sensitive to the interface roughness and is least sensitive for $\mathrm{H}$ piles. The maximum $N_{\mathrm{p}_{-} \mathrm{FE}}$ values for circular piles of 12.5 and 11.5 at $\alpha=1$ and 0.5 are $5 \%$ larger than the respective values of 11.9 and $10 \cdot 8$ derived by Martin \& Randolph (2006) using classical plasticity. Unlike the circular pile, the $N_{\text {p_FE }}$ values for the square and $\mathrm{H}$ piles tend to continue to show modest 
increases in magnitude up to $z / B=6$; such a tendency was predicted in the solutions of Murff \& Hamilton (1993) and was also indicated for all pile shapes by the centrifuge $N_{\mathrm{p}_{-} \text {Tbar }}$ values in Fig. 4.

The calculated load-displacement responses of the square and $\mathrm{H}$ piles are seen in Fig. 9 to be stiffer than for the circular piles, despite each analysis having the same

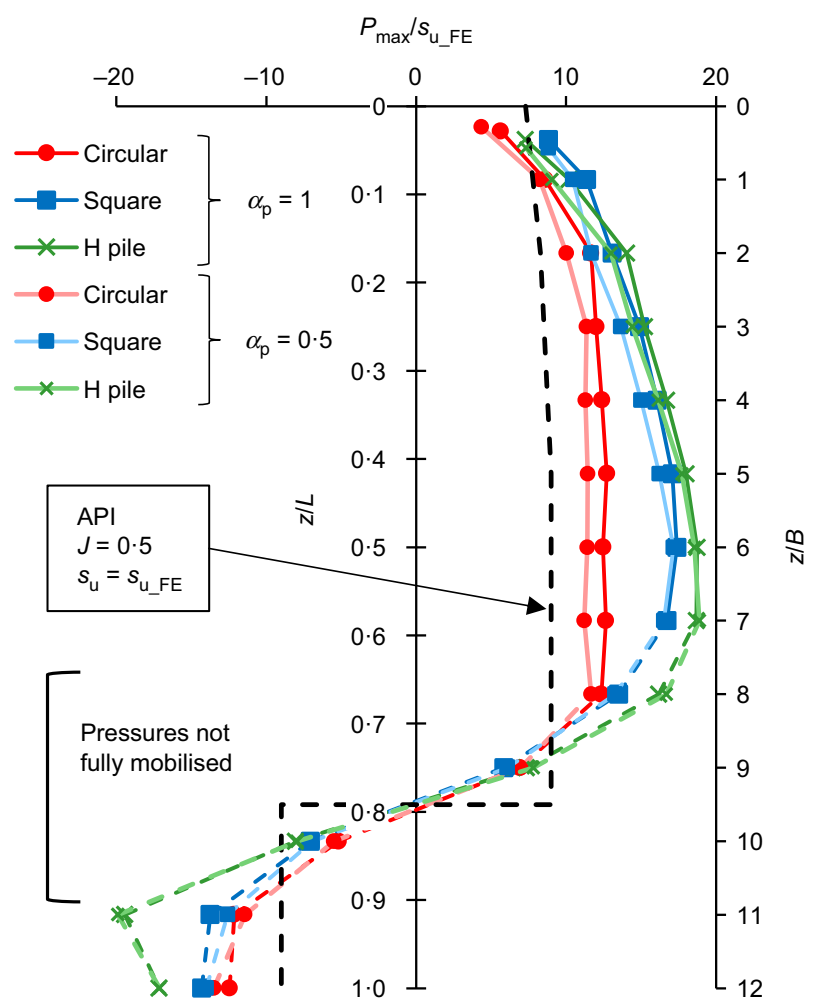

Fig. 10. Finite-element calculations for the lateral pile capacity factor (and a comparison with API (2011)) linear Young's modulus profile $\left(E_{\mathrm{u}}\right)$. This observation reflects differences in soil deformation paths associated with each of the three pile shapes. The centrifuge experiments also showed a stiffer load-displacement response for the square and $\mathrm{H}$ piles, but the effect was less pronounced when calculated using the linear elastic-perfectly plastic model.

Additional insights into the effect of shape can be drawn from the analysis of a square pile which is loaded normal to the diagonal and where the diagonal width is the same as that of the square pile with loading normal to one side. The EI value for both piles was held constant (see Table 2). It is seen in Fig. 9 that the response of the rotated pile (i.e. loaded normal to its diagonal) is almost identical to that of the fully rough, circular pile. This response suggests that the soil failure modes for both these cases are very similar.

The difference between the flow-around failure modes for each pile shape is illustrated in Fig. 11, which presents computed displacement vectors on the horizontal plane at $z / B=5$ at ultimate conditions. It can be seen that the circular section and the square section loaded on the diagonal encourage a rotational soil movement at short distances from the centreline. In contrast there is a greater tendency for lateral translation across the full widths of the square and $\mathrm{H}$ piles and consequently a much larger radius for the rotational mechanism developed at ultimate conditions. Generation of this wider mechanism requires more energy and gives rise to the interpretation of higher net ultimate pressures and $N_{\mathrm{p}}$ values. The slightly less constrained movement of clay between the flanges of the $\mathrm{H}$ pile explains why its $N_{\mathrm{p}}$ value is marginally greater than that of a square pile.

\section{OPERATIONAL UNDRAINED SHEAR STRENGTH}

It is of interest to compare the ultimate net pressures $\left(P_{\mathrm{u}}\right)$ recorded in the centrifuge tests with those calculated in the finite-element analyses and with API (2011), which recommends a maximum $N_{\mathrm{p}}$ value $\left(P_{\mathrm{u}} / s_{\mathrm{u} \_ \text {UU }}\right)$ of 9 for flow-around conditions (see equation (1)).

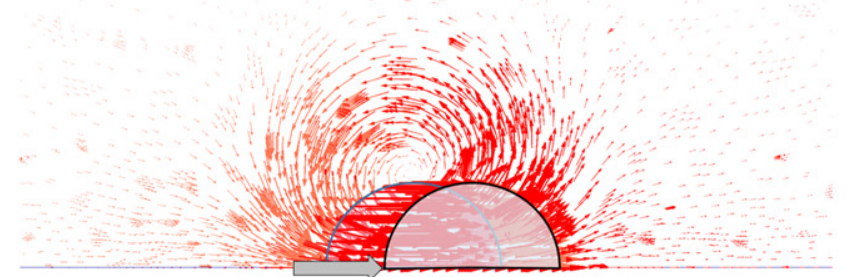

(a)

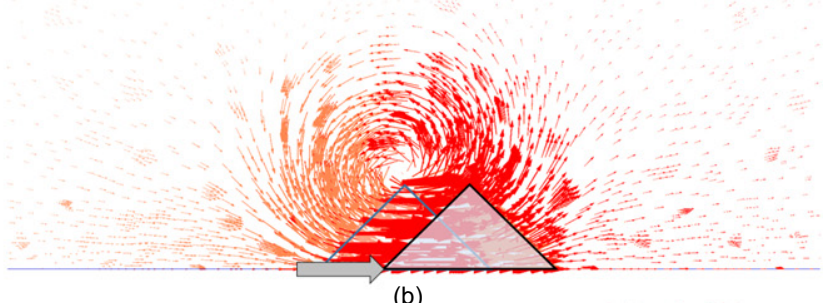

(b)

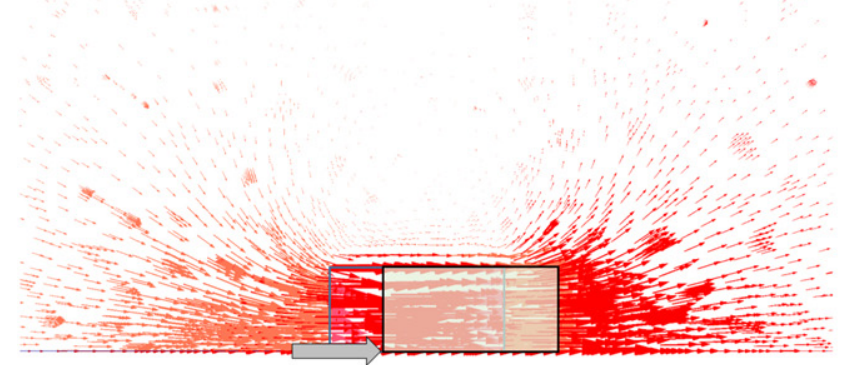

(c)

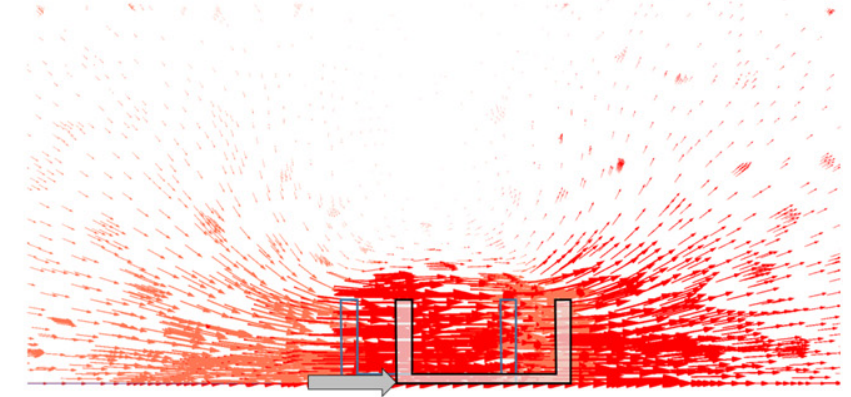

(d)

Fig. 11. Displacement vectors at $z / B=5 \cdot 7$ : (a) circular; (b) rotated square; (c) square; (d) $\mathrm{H}$ pile 
The profile of undrained shear strength specified in the finite-element analyses was $s_{\mathrm{u}_{-} \mathrm{FE}}=1.4 \mathrm{kPa} / \mathrm{m}$, which is the same as the mean T-bar strength profile for OCR $=1$ clay. Computed values of $P_{\mathrm{u}}$ with $\alpha$ between 0.5 and 1 for a circular pile are within $10 \%$ of those inferred from the centrifuge tests, although it is noted that these tests display a gradual increase in $N_{\mathrm{p}}$ with depth that is not observed in the finite-element analyses. This comparison suggests that the operational strength $\left(s_{\mathrm{u}_{-} \mathrm{op}}\right)$ in the vicinity of the circular pile (i.e. the strength that should be input to the finite-element analysis to predict the centrifuge pile response) is comparable to that of a T-bar.

Undrained triaxial test data for kaolin (e.g. Lehane et al., 2009) indicate that the undrained strength ratio of both isotropically and anisotropically normally consolidated samples of kaolin ranges from $0 \cdot 25$ to $0 \cdot 3$, with an average value of $0 \cdot 275$. This average ratio gives a strength gradient for consolidated undrained strength $\left(s_{\mathrm{u}_{-} \mathrm{CU}}\right)$ of $1.65 \mathrm{kPa} / \mathrm{m}$, which is 1.17 times greater than $s_{\mathrm{u} \_ \text {Tbar. }}$ The ultimate pressure ratios for the centrifuge tests calculated using $s_{\mathrm{u} \_\mathrm{CU}}$ rather than $s_{\mathrm{u} \_ \text {Tbar }}$ (i.e. $N_{\mathrm{p} \_\mathrm{CU}}=P_{\mathrm{u}} / s_{\mathrm{u} \_\mathrm{CU}}$ ) are presented in Fig. 12, where they are seen, for circular piles, to give a mean stabilised $N_{\mathrm{p}}$ value at depth (i.e. corresponding to full flowaround) of $10 \cdot 5$, which is more in line with the design value of 9 recommended in API (2011) and used commonly in practice. However, as indicated in equation (1), API (2011) employs the unconsolidated undrained triaxial strength

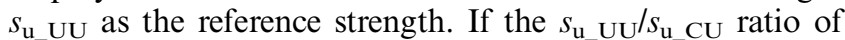
$0 \cdot \overline{7}$ recommended by Chen \& Kulhawy (1993) is adopted, the corresponding $N_{\mathrm{p}}$ value at depth shown in the centrifuge tests is 15 ; that is, $66 \%$ higher than the recommended value.

The foregoing suggests that the operational strength in the vicinity of a lateral loaded pile in soft clay is comparable to the undrained strength measured in a T-bar. However, a slightly lower $N_{\mathrm{p}}$ value should be used when relating

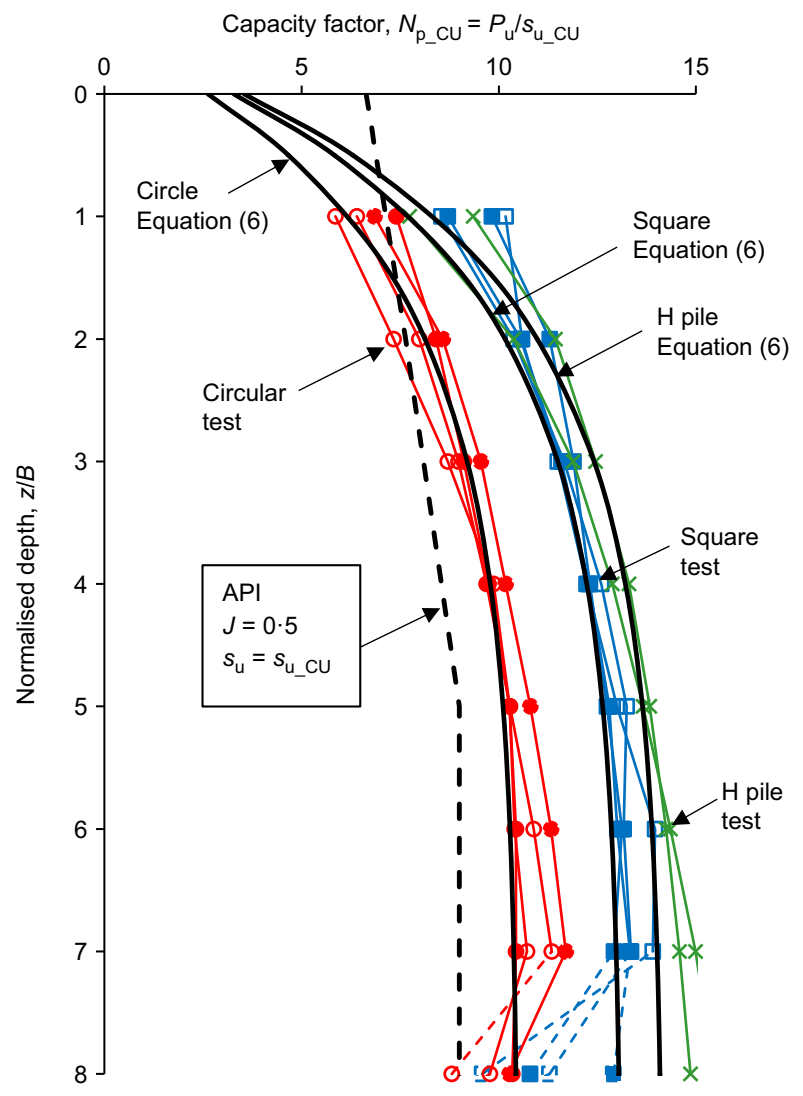

Fig. 12. Lateral pile capacity factor normalised with $s_{\mathbf{u} \_C U}$ net ultimate pressures to undrained strengths measured in triaxial compression on samples consolidated to their in situ stress state $\left(s_{\mathrm{u}_{-} \mathrm{CU}}\right)$. It is also noted that the experimental $N_{\text {p_CU }}$ values for circular piles are within $10 \%$ of the finiteelement analyses as well as the numerical solutions of Randolph \& Houlsby (1984), Murff \& Hamilton (1993) and Martin \& Randolph (2006).

\section{PROPOSED $p-y$ FORMULATION}

A $p-y$ formulation for soft clays is presented here using the value of $s_{\mathrm{u} \_\mathrm{CU}}$ as the reference undrained strength. This strength is used because of the popularity of the triaxial compression test and the declining practice of relying on UU strengths due to well-known losses in effective stress that occur during tube sampling. A circular pile is used as the base case for the formulation for which the flow-around value of $N_{\text {p_Cu }}$ at depth in the centrifuge tests averaged at about $10 \cdot 5$.

Equation (6) was found by regression analysis of the centrifuge $P_{\mathrm{u}}$ data bearing in mind the observation that the ratio of the ultimate net lateral soil pressure $\left(P_{\mathrm{u}}\right)$ to undrained shear strength in soft clays is independent of the OCR (for OCR $\leq 2$ ) and the installation mode (at least for $z / B<3$ ), but varies with depth, pile shape and pile roughness. $P_{\mathrm{u}}$ is taken to vary with normalised depth $(z / B)$, rather than soil depth (z), which is in accordance with results from finite-element analyses involving lateral tests on piles with different widths (e.g. as reported by Truong \& Lehane (2014), and others).

$$
\frac{P_{\mathrm{u}}}{S_{\mathrm{u}_{-} \mathrm{CU}}}=10 \cdot 5\left[1-0.75 \mathrm{e}^{-0.6 z / B}\right] S_{\mathrm{p}}
$$

$S_{\mathrm{p}}$ is a shape correction factor $=1 \cdot 0$ for a circular pile, 1.25 for a square pile and 1.35 for an $\mathrm{H}$ pile

Equation (6) is compared in Fig. 12 with the results from the centrifuge experiments for the three pile shapes and two OCRs investigated (noting that cracks do not occur on the active side at these OCRs). It is evident that equation (6) provides a reasonable fit to all centrifuge data and finite-element calculations. As the centrifuge $P_{\mathrm{u}}$ data at very shallow depths are prone to experimental error, the finite-element results were used to inform the regression analysis for $z / B<2$ and gave $N_{\mathrm{p}}$ factors of 2.75 for the circular pile and 3.85 for an $\mathrm{H}$ pile at the clay surface $(z=0)$. Slightly higher ultimate pressures than those given by equation (6) may be expected for piles with a roughness greater than the aluminium centrifuge piles.

The full set of $P / P_{\mathrm{u}}-y / B$ curves obtained between $z / B$ of 2 and 6 in the centrifuge tests are plotted in Fig. 13. It has previously been seen that these normalised curves do not depend in any obvious way on the normalised depth $(z / B)$, pile shape, pile end condition and clay. Although the spread of curves appears significant in Fig. 13, the following best-fit function to all curves has a correlation coefficient, $r^{2}$, of 0.96

$$
\frac{P}{P_{\mathrm{u}}}=\tanh \left[5.45\left(\frac{y}{B}\right)^{0.52}\right]
$$

Figure 13 also presents the $P / P_{\mathrm{u}}-y / B$ curve recommended by API (2011) for clay using $\varepsilon_{50}$ values of 0.005 and 0.02 , where $\varepsilon_{50}$ is the strain to reach $50 \%$ of the mobilised strength in an undrained triaxial compression test. It is interesting to note that $\varepsilon_{50}$ values measured in triaxial tests on the UWA kaolin ranged from 0.001 to 0.004 with an average value of $0 \cdot 002$. Matlock (1970) suggests $\varepsilon_{50}$ of 0.02 for soft clays, but the value of $0 \cdot 005$, which was recommended for stiff clays, provides the closest match to the experimental results. 


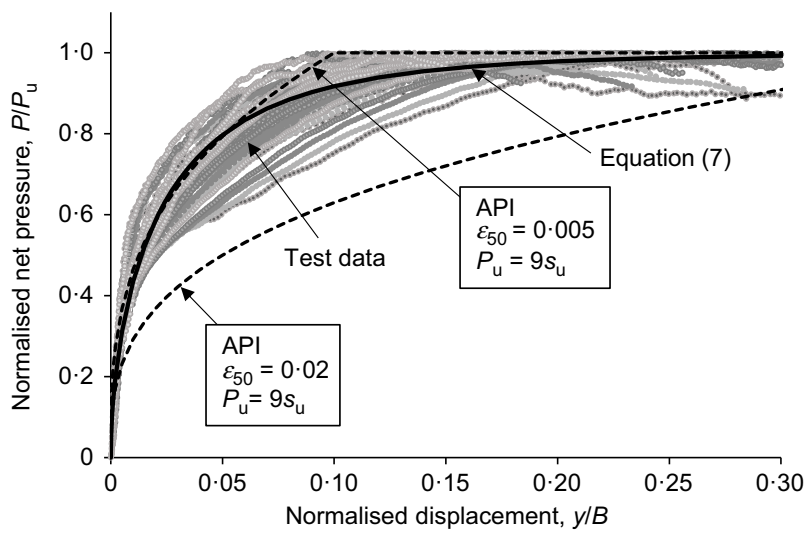

Fig. 13. Normalised $P-y$ curve comparison from centrifuge tests, API and equation (5)

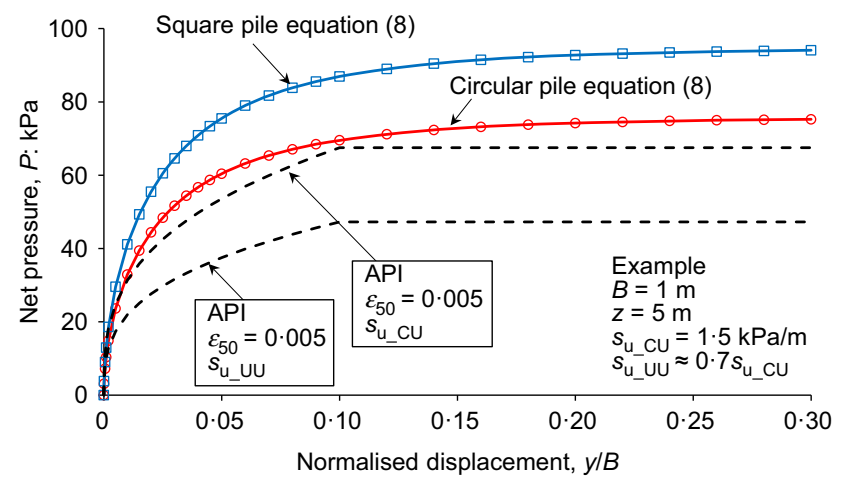

Fig. 14. $P-y$ curve comparison example at depth of $z / B=5$

Equations (6) and (7) are combined to give the following $P-y$ relationship

$$
P=10 \cdot 5 s_{\mathrm{u}_{-} \mathrm{CU}} \tanh \left[5 \cdot 45\left(\frac{y}{B}\right)^{0.52}\right]\left[1-0.75 \mathrm{e}^{-0.6 z / B}\right] S_{\mathrm{p}}
$$

The $P-y / B$ responses calculated at $z / B=5$ for an example case with $B=1 \mathrm{~m}$ are compared in Fig. 14 with the $P-y / B$ curve recommended by API (2011). It is seen that the API (2011) curve with $\varepsilon_{50}=0.005$ and $N_{\mathrm{p}}=9$ provides a reasonably conservative estimate of the curve for the circular pile, when the $s_{\mathrm{u}_{-} \mathrm{CU}}$ strength is used in place of $s_{\mathrm{u} \_ \text {UU }}$. Using the $s_{\mathrm{u} \_\mathrm{UU}} / s_{\mathrm{u} \_\mathrm{CU}}$ ratio of $0 \cdot 7$, referred to above, the API (2011) recommendations obtained using $s_{\mathrm{u}_{-} \mathrm{UU}}$ are seen on Fig. 14 to lead to a very conservative $P-y / B$ response. The figure also highlights the significant benefits of using a square sectioned pile.

\section{CONCLUSIONS}

(a) The results from a series of centrifuge lateral pile tests in kaolin supported by finite-element analyses clearly illustrate the importance of pile shape on the lateral load transfer $(P-y)$ curves. Higher net pressures can develop for square and $\mathrm{H}$ piles compared to circular piles and this arises because of the larger volume of clay per unit pile width involved in the failure mechanisms surrounding the square and $\mathrm{H}$ pile sections.

(b) Notwithstanding potential differences associated with pile installation at $1 \mathrm{~g}$, the centrifuge tests also showed that the end condition for a displacement pile has no discernible effect on the subsequent $P-y$ response at $z / B<3$; assessments of effects at deeper levels could not be made because open-ended piles plugged at these levels.

(c) The centrifuge tests indicated approximately the same net ultimate pressures $\left(P_{\mathrm{u}}\right)$ as finite-element analyses when the T-bar strengths are input to the analyses - that is, the operational strength is equal to $s_{\mathrm{u}_{-} \text {Tbar }}$. This operational strength is, however, lower than usually inferred from consolidated triaxial compression tests $\left(s_{\mathrm{u} \_} \mathrm{CU}\right)$ and hence a lower ratio of $P_{\mathrm{u}}$ to undrained strength needs to be adopted when $s_{\mathrm{u} \_\mathrm{CU}}$ is used as the reference strength.

(d) The centrifuge experiments did not reveal any systematic dependence of $P / P_{\mathrm{u}}$ plotted against $y / B$ curves on $z / B$, pile shape, pile end condition and clay OCR, over the range of parameters investigated. This result, combined with the observed dependence of net ultimate pressures on normalised depth, pile shape and undrained shear strength, was used to develop a new $P-y$ equation for piles in soft clay (equation (8)). This equation is shown to be reasonably consistent with API (2011) recommendations for circular piles if $\varepsilon_{50}$ is taken as 0.005 and $s_{\mathrm{u}_{-} \mathrm{CU}}$ is used in place of $s_{\mathrm{u}_{-} \mathrm{UU}}$. The shape factor included in equation (8) reflects the importance of allowing for the effects of pile shape when evaluating $P-y$ curves.

\section{ACKNOWLEDGEMENTS}

The authors are grateful for the funding provided by the Australian Research Council. The authors would also like to acknowledge the valuable contributions of Dr Fengju Guo to the centrifuge testing.

\begin{tabular}{|c|c|}
\hline NOTATI & $\mathrm{DN}$ \\
\hline$B$ & pile width \\
\hline$D$ & pile diameter \\
\hline$E_{\mathrm{p}}$ & Young's modulus of pile \\
\hline$E_{\mathrm{u}}$ & undrained Young's modulus of soil \\
\hline$E I$ & flexural rigidity of the pile \\
\hline$e$ & load eccentricity from soil surface \\
\hline$I$ & second moment of area of pile \\
\hline$J$ & dimensionless empirical constant \\
\hline$k$ & rate of increase of undrained shear strength with depth \\
\hline$L$ & pile embedment length \\
\hline$M$ & pile bending moment \\
\hline$N_{k}$ & cone factor \\
\hline$N_{\mathrm{p}}$ & lateral pile capacity factor $=P_{\mathrm{u}_{\mathrm{u}}} / s_{\mathrm{u}_{-} \mathrm{UU}}$ \\
\hline$N_{\text {p_CU }}$ & lateral pile capacity factor $=P_{\mathrm{u}} / s_{\mathrm{u}_{\_} \mathrm{CU}}$ \\
\hline$N_{\mathrm{p}_{-} \mathrm{FE}}$ & lateral pile capacity factor $=P_{\mathrm{u}} / s_{\mathrm{u}_{-} \mathrm{FE}}$ \\
\hline $\begin{array}{r}N_{\mathrm{p}_{-} \text {Tbar }} \\
P\end{array}$ & $\begin{array}{l}\text { lateral pile capacity factor }=P_{\mathrm{u}_{\mathrm{u}}} / s_{\mathrm{u}_{-} \text {Tbar }} \\
\text { net soil pressure }\end{array}$ \\
\hline$P_{\mathrm{u}}$ & ultimate net soil pressure \\
\hline$p$ & net soil resistance per unit length \\
\hline$q_{\mathrm{c}}$ & cone penetration resistance \\
\hline$r^{2}$ & correlation coefficient \\
\hline$s_{\mathrm{u}}$ & undrained shear strength \\
\hline$S_{\mathrm{u} \_\mathrm{CU}}$ & consolidated isotropic undrained triaxial shear strength \\
\hline$s_{\mathrm{u}_{\perp} \mathrm{FE}}$ & $\begin{array}{l}\text { undrained shear strength specified in finite } \\
\text { element analysis }\end{array}$ \\
\hline$s_{\mathrm{u}_{-} \mathrm{op}}$ & operational undrained shear strength \\
\hline$s_{\mathrm{u} \_ \text {Tbar }}$ & T-bar undrained shear strength \\
\hline $\begin{array}{r}s_{\mathrm{u}_{-} \mathrm{UU}} \\
\left(s_{\mathrm{u}} / \sigma_{\mathrm{v}}^{\prime}\right)_{\mathrm{N} C}\end{array}$ & unconsolidated undrained triaxial shear strength \\
\hline$\left(s_{\mathrm{u}} / \sigma_{\mathrm{v}}\right)_{\mathrm{NC}}$ & $\begin{array}{l}\text { undrained shear strength ratio for normally } \\
\text { consolidated clay }\end{array}$ \\
\hline$t$ & pile wall thickness \\
\hline$y$ & lateral displacement \\
\hline 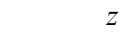 & depth below soil surface \\
\hline
\end{tabular}



$\alpha$ pile roughness parameter
$\varepsilon_{50}$ strain at $50 \%$ strength
$\sigma_{\mathrm{v}}^{\prime} \quad$ vertical effective stress

\section{REFERENCES}

Anderson, J. B., Townsend, F. C. \& Grajales, B. (2003). Case history evaluation of laterally loaded piles. J. Geotech. Geoenviron. Engng 129, No. 3, 187-197.

API (American Petroleum Institute) (2011). ISO 19901-4: Geotechnical and foundation design considerations. API recommended practice $2 G E O$, 1 st edn. Washington, DC, USA: API Publishing Services.

Chen, Y. J. \& Kulhawy, F. H. (1993). Undrained strength Interrelationships among CIUC, UU, and UC tests. J. Geotech. Engng 119, No. 11, 1732-1750.

Choi, Y., Basu, D., Salgado, R. \& Prezzi, M. (2014). Response of laterally loaded rectangular and circular piles in soils with properties varying with depth. J. Geotech. Geoenviron. Engng 140, No. 4, 04013049.

Fan, C. \& Long, J. H. (2005). Assessment of existing methods for predicting soil response of laterally loaded piles in sand. Comput. Geotech. 32, No. 4, 274-289.

Fleming, K., Weltman, A., Randolph, M. F. \& Elson, K. (2009). Piling engineering, 3rd edn. Abingdon, UK: Taylor \& Francis.

Gabr, B. M. A., Lunne, T. \& Powell, J. J. (1994). $P-y$ analysis of laterally loaded piles in clay using DMT. J. Geotech. Engng 120, No. 5, 816-837.

Jeanjean, P. (2009). Re-assessment of $p-y$ curves for soft clays from centrifuge testing and finite element modeling. Proceedings of the offshore technology conference, Houston, TX, USA, paper OTC 20158.

Ladd, C. C., Foot, R., Ishihara, K., Schlosser, F. \& Poulos, H. G. (1977). Stress-deformation and strength characteristics. In Proceedings of the 9 th international conference on soil mechanics and foundation engineering, Tokyo, Japan, vol. 2, pp. 421-494. Tokyo, Japan: Japanese Society of Soil Mechanics and Foundation Engineering.

Lehane, B. M., O'Loughlin, C. D., Randolph, M. F. \& Gaudin, C. (2009). Rate effects on penetrometer resistance in kaolin. Géotechnique 59, No. 1, 41-52, https://doi.org/10.1680/geot. 2007.00072.

Martin, C. M. \& Randolph, M. F. (2006). Upper-bound analysis of lateral pile capacity in cohesive soil. Géotechnique 56, No. 2, 141-145, https://doi.org/10.1680/geot.2006.56.2.141.

Matlock, H. (1970). Correlation for design of laterally loaded piles in soft clay. Proceedings of the offshore technology conference, Houston, TX, USA, paper OTC 1204.

Murff, J. D. \& Hamilton, J. M. (1993). P-ultimate for undrained analysis of laterally loaded piles. J. Geotech. Engng 119, No. 1, 91-107.
Oasys (2014). ALP version 19.2 build 11. Newcastle, UK: Arup Group Limited.

Plaxis (2015). Plaxis $3 D$ anniversary edition. Delft, the Netherlands: Plaxis bv.

Poulos, H. G. \& Hull, T. (1989). The role of analytical geomechanics in foundation engineering. In Foundation engineering: current principles and practices (ed. F. H. Kulhawy), GSP No. 22, pp. 1578-1606. New York, NY, USA: American Society of Civil Engineers.

Randolph, M. F. \& Houlsby, G. T. (1984). The limiting pressure on a circular pile loaded laterally in cohesive soil. Géotechnique 34, No. 4, 613-623, https://doi.org/10.1680/geot.1984.34.4.613.

Reese, L. C. \& Van Impe, W. F. (2011). Single piles and pile groups under lateral loading, 2nd edn. Boca Raton, FL, USA: Taylor \& Francis.

Stewart, D. P., Boyle, R. S. \& Randolph, M. F. (1998). Experience with a new drum centrifuge. In Centrifuge '98: proceedings of the international conference, IS-Tokyo ' 98 (eds T. Kimura, O. Kusakabe and J. Takemura), pp. 35-40. Rotterdam, the Netherlands: Balkema.

Suryasentana, S. K. \& Lehane, B. M. (2016). Updated CPT based $p-y$ formulation for laterally loaded piles in cohesionless soil under static loading. Géotechnique 66, No. 6, 445-443, https://doi.org/10.1680/jgeot.14.P.156.

Taylor, R. N. (ed.) (1995). Geotechnical centrifuge technology. Glasgow, UK: Chapman \& Hall.

Templeton, J. (2009). Finite element analysis of conductor/seafloor interaction. Proceedings of the offshore technology conference, Houston, TX, USA, paper OTC-20197.

Tomlinson, M. \& Woodward, J. (2014). Pile design and construction practice, 6th edn. Boca Raton, FL, USA: Taylor \& Francis Group.

Truong, P. \& Lehane, B. M. (2014). Numerically derived CPT based $p-y$ curves for a soft clay modeled as an elastic perfectly plastic material. In Proceedings of the third international symposium on cone penetration testing (CPT'14), Las Vegas, NV, USA (eds P. K. Robertson and K. Cabal), pp. 975-982. Madison, WI, USA: Omnipress.

Tzivakos, K. P. \& Kavvadas, M. J. (2014). Numerical investigation of the ultimate lateral resistance of piles in soft clay. Frontiers Struct. Civ. Engng 8, No. 2, 194-200.

White, D. J., Gaudin, C., Boylan, N. \& Zhou, H. (2010). Interpretation of T-bar penetrometer tests at shallow embedment and in very soft soils. Can. Geotech. J. 47, No. 2, 218-229.

Zhao, X., Gaudin, C., Randolph, M. \& O’Loughlin, C. D. (2016). Factors influencing T-bar measurements in geotechnical centrifuge. In Proceedings of the 3rd European conference on physical modelling in geotechnics (EUROFUGE 2016) (eds L. Thorel, A. Bretschneider, M. Blanc and S. Escoffier), pp. 91-98. Nantes, France: IFSTTA Nantes. 